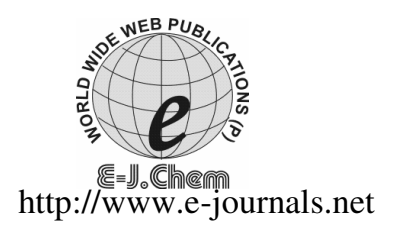

ISSN: 0973-4945; CODEN ECJHAO

E-Journal of Chemistry

2011, 8(3), 1068-1073

\title{
Morphological Characterization of Soot from the Atmospheric Combustion of Kerosene
}

\author{
EZEKIEL DIXON DIKIO \\ Department of Chemistry, Vaal University of Technology \\ P. O. Box X021, Vanderbijlpark, South Africa \\ ezekield@vut.ac.za
}

Received 9 December 2010; Accepted 23 January 2011

\begin{abstract}
Kerosene has been used as a precursor for the production of carbon nanomaterial without a catalyst precursor. Nanomaterials formed in the process have been analysed by Raman, Scanning electron microscope (SEM), $\mathrm{x}$-Ray diffraction (XRD) and by Energy dispersive spectroscopy (EDS). Carbon nanomaterial produced show the morphology of carbon nanospheres with diameters of about $0.3 \mu \mathrm{m}$.
\end{abstract}

Keywords: Kerosene, SEM, Carbon nanomaterial, XRD, Raman spectra, EDS

\section{Introduction}

Kerosene which is obtained from the fractional distillation of crude oil constitutes one of the most important fuels used in heating and as a fuel ${ }^{1}$. Kerosene is a complex mixture of aromatic and aliphatic hydrocarbons with carbon numbers predominantly in the $\mathrm{C}_{9}-\mathrm{C}_{16}$ range ${ }^{2}$. Many workers had accidentally observed carbon nanomaterials and fibers in deposits inside furnaces dealing with hydrocarbon gases ${ }^{3}$. These products were found growing on graphite rods, quartz tubes, ceramic tubes, fire bricks and other materials of iron, cobalt, nickel or any other material present in the reaction zone ${ }^{3}$. Carbon nanotubes and fibers are being fabricated by the pyrolysis of acetylene ${ }^{4-6}$, methane ${ }^{7}$, ethanol ${ }^{8}$, benzene ${ }^{9}$ and carbonization of synthetic polymers, such as polyvinyl alcohol (PVA) ${ }^{10}$ among others. Carbon nanospheres (CNS), on the other hand, have a semi-crystalline structure which is a reflection of their unique properties of low density, high porosity, increased surface area and relatively high chemical and thermal stability ${ }^{11,12}$. CNS and carbon nanotubes can be made by a variety of procedures and these include numerous variations of the arc-discharge, laser ablation and chemical vapor deposition processes with inorganic metals and in some instances organometallic complexes are used as catalysts in these methods. The catalysts are generally made from metals or their salts ${ }^{13}$. Hydrocarbons are by far the most widespread precursors among carbon sources employed in the production of carbon nanotubes and carbon nanospheres. 
Most of these process are either unsuitable for large scale production of carbon nanotubes or nanomaterials and are expensive. There is therefore a need to find a cheap source and a simple technique to synthesize carbon nanomaterials. In this study, commercial kerosene which is cheap and locally available is investigated as a precursor for the production of carbon nanomaterials.

\section{Experimental}

Kerosene used in this study was purchased from shell garage in Vanderbijlpark, Republic of South Africa and used without further purification.

\section{Preparation of nanomaterials}

Commercial kerosene was placed in a simple laboratory lamp with a combustible cylindrical cotton material. The lamp was left for $24 \mathrm{~h}$ to absorb the kerosene. The lamp was lighted with a match and allowed to burn. A flat ceramic tile plate was placed above the flame of the lamp to collect soot emitted from the lamp. When an amount of soot approximately equal to $10 \mathrm{~g}$ was collected, the experiment was terminated.

\section{Characterization}

The morphological features of nanomaterials were analyzed by Raman spectroscopy, FE-SEM, EDS and XRD. The Raman spectra were obtained by a Raman spectroscope, Jobin-Yvon HR800 UV-VIS-NIR Raman spectrometer equipped with an Olympus BX 40 attachment. The excitation wavelength was $514.5 \mathrm{~nm}$ with an energy setting of $1.2 \mathrm{mV}$ from a coherent innova model 308 argon-ion laser. The Raman spectra were collected by means of back scattering geometry with an acquisition time of 50 seconds. The surface morphology and EDS measurements were recorded with a JEOL 7500F Field Emission scanning electron microscope. Powder X-ray diffraction (PXRD) patterns were collected with a Bruker AXS D8

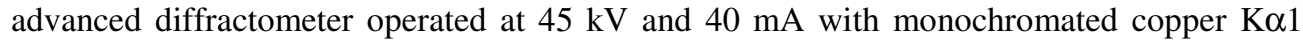
radiation of wavelength $(\lambda=1.540598)$ and $\mathrm{K} \alpha 2$ radiation of wavelength $(\lambda=1.544426)$. Scan speed of $1 \mathrm{~s} / \mathrm{step}$ and a step size of $0.03^{\circ}$.

\section{Results and Discussion}

Burning of kerosene to obtain soot is a thermal decomposition process in which the kerosene breaks up to form other substances. The air borne thermolytic particles are extremely small and occur individually. Some particles are seen to form aggregates on the ceramic collector plate. Particles obtained from the atmospheric combustion of kerosene are a complex mixture of elemental carbon, a variety of hydrocarbons, silicon compounds and other species $^{14}$.

The FE-SEM micrograph of kerosene thermolytic carbon nanomaterial is presented in Figure 1. The surface morphology of the carbon deposit obtained is seen to be non-uniform. There are several grains with what looks like carbon nanotube formed in this Figure. The kerosene soot particles are extremely small with a majority of the particles about $0.3 \mu \mathrm{m}$ in diameter. The FE-SEM image of soot particles at $100 \mathrm{~nm}$ and $1 \mu \mathrm{m}$ show particles of carbon which are chain-like agglomerations as shown in Figure 1.

Energy dispersive spectroscopy (EDS) of kerosene soot is presented in Figure 2. The spectra show the presence of carbon and oxygen as the combustion product of kerosene. The composition of the soot aggregates from the EDS analysis indicates the soot to consist of about $27.17 \%$ weight carbon and $72.63 \%$ weight of oxygen and $0.20 \%$ weight of silicon. 


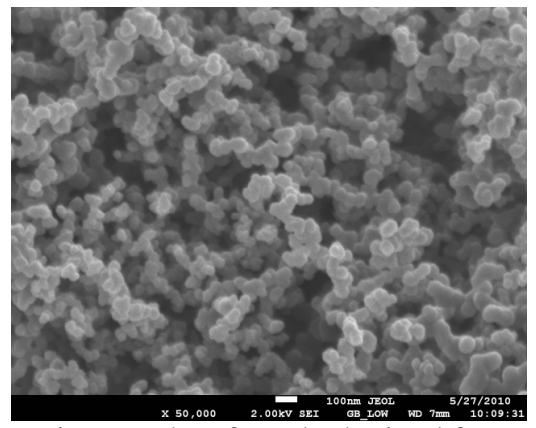

Figure 1. Scanning electron micrographs of sooth obtained from the combustion of kerosene Full scale counts: 6577 Kerosene(1)

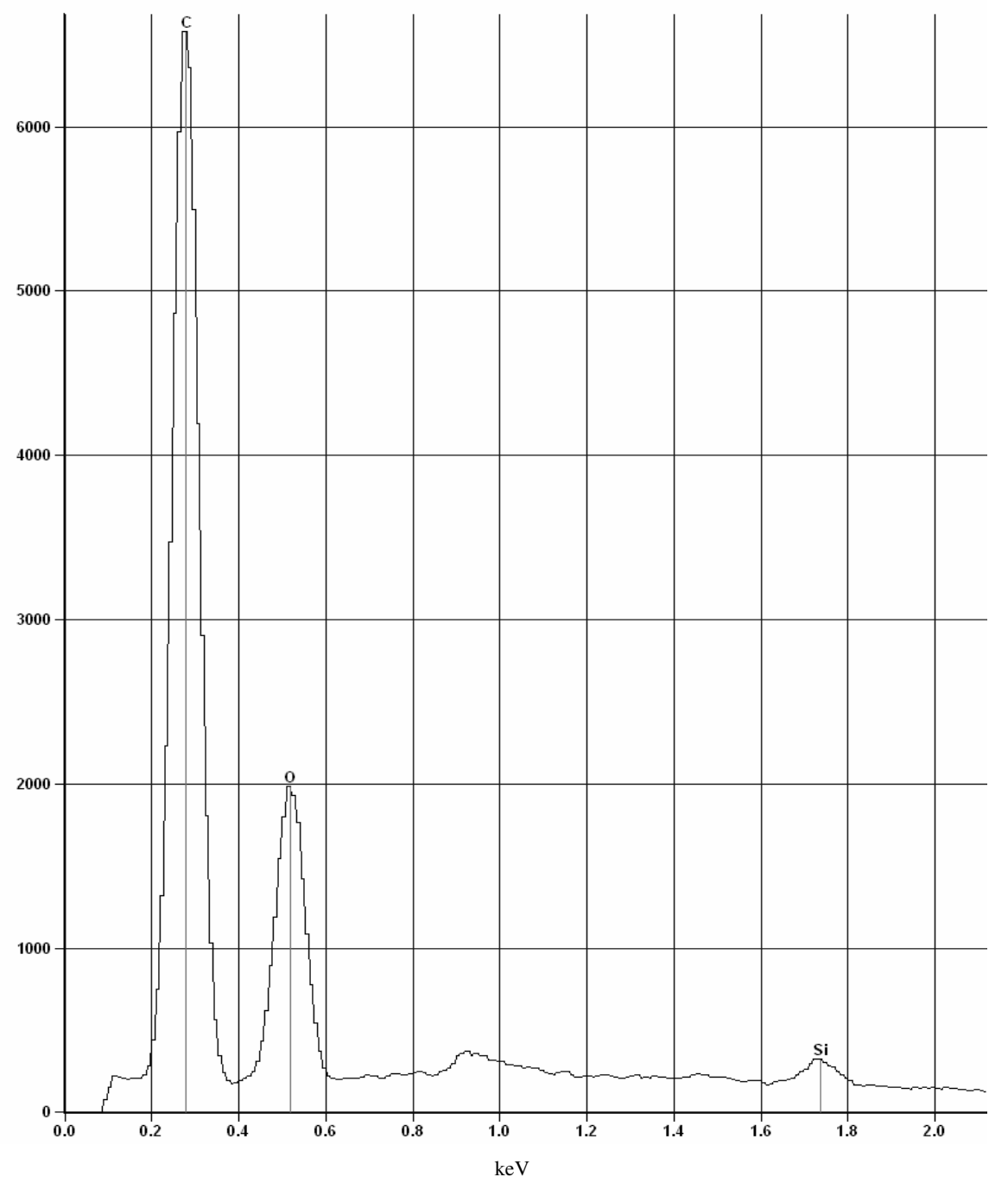

Figure 2, Energy dispersive x-ray spectra of sooth obtained from the combustion of kerosene 
The result shows the product of the thermal decomposition of kerosene to be composed mainly of carbon and oxygen with a small percentage of silicon, Figure 2 and Table 1 . The origin of silicon in this investigation is not known at this moment.

Table 1. Table of energy dispersive spectroscopy of kerosene soot

\begin{tabular}{ccc}
\hline Element & Element, \% weight & Atom, \% \\
\hline Carbon $(\mathrm{C})$ & 27.17 & 33.23 \\
Oxygen $(\mathrm{O})$ & 72.63 & 66.67 \\
Silicon $(\mathrm{Si})$ & 0.20 & 0.11 \\
Total & 100 & 100 \\
\hline
\end{tabular}

The Raman spectrum of the kerosene soot is presented in Figure 3. The Raman spectra show two major bands at $1330.34 \mathrm{~cm}^{-1}$ and $1583.88 \mathrm{~cm}^{-1}$. These bands are the $D$ and $G$ bands which indicate the presence of crystalline graphitic carbon in synthesized carbon nanotubes. The $D$ band at $1330.34 \mathrm{~cm}^{-1}$ has been attributed to the presence of amorphous carbon $^{8,15,16}$ and surface defects in carbon nanotubes. The $G$ band at $1583.88 \mathrm{~cm}^{-1}$ correspond to an $e_{2 g}$ mode of graphite which is related to the vibration of $\mathrm{sp}^{2}$-bonded carbon atoms and the presence of ordered carbon nanotubes in a sample. The band at $1330.34 \mathrm{~cm}^{-1}$ of moderate intensity is associated with vibrations of carbon atoms in disordered graphite. The $D$ and $G$ bands should produce an overtone which resonates at about $2600 \mathrm{~cm}^{-1}$. The presence of this resonance peak in the Raman spectra of a CNTs synthesis could be related to the amount of carbon nanotubes produced in the synthesis as well as their purity. The absence of this resonance peak in the soot obtained from kerosene combustion is an indication that the kerosene soot had formed impure as well as few carbon nanotubes in the process. The intensity ratio of these two bands $\left(I_{D} / I_{G}=0.8399\right)$ is also considered as a parameter to characterize the quality of CNTs in the samples under investigation. A high intensity ratio would indicate a higher degree of disorder in the CNTs. The intensity ratio for the two bands obtained, 0.8399 , shows that a low percentage of CNTs were formed in the kerosene soot obtained. The intensity of the two peaks are quite high indicating that there exits two dimensional disorder in the carbon nanomaterial produced from this thermolytic process.

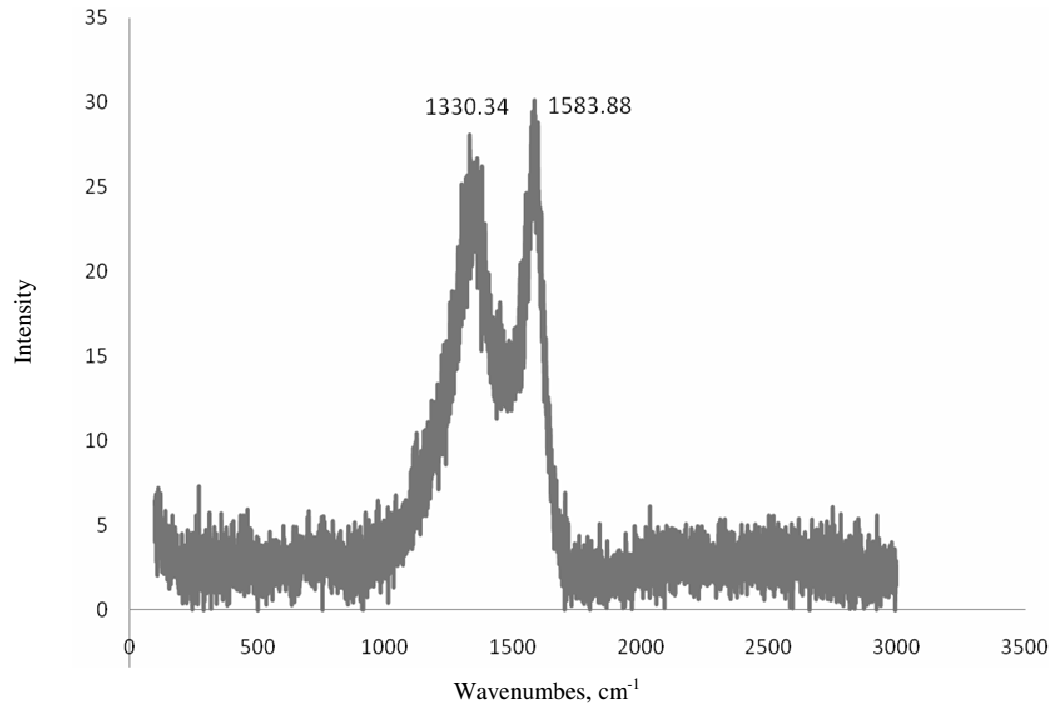

Figure 3. Raman spectra of sooth obtained from the combustion of kerosene 
The x-ray diffraction (XRD) pattern of kerosene soot is shown in Figure 4. The carbonaceous soot obtained was used directly. The Bragg diffraction peaks at $2 \theta=23.68^{\circ}$, $42.33^{\circ}$ are the only notable peaks obtained in this x-ray diffraction analysis. The peaks at $2 \theta=23.68^{\circ}$ and $42.33^{\circ}$ correspond to hexagonal graphite lattice of multi-walled carbon nanotubes ${ }^{17,18}$. The peak at $2 \theta=23.68^{\circ}$ is a moderately high intensity broad peak which indicates the presence of large amounts of amorphous material in association with nanotubes. The low intensity of the peak at $2 \theta=42.33^{\circ}$, is an indication of the low quality of carbon nanomaterial present in the soot. Reflections in Figure 4 could also be indexed as (002) and (101). The peak at (002) is strong while the peak at (101) is weak ${ }^{19}$.

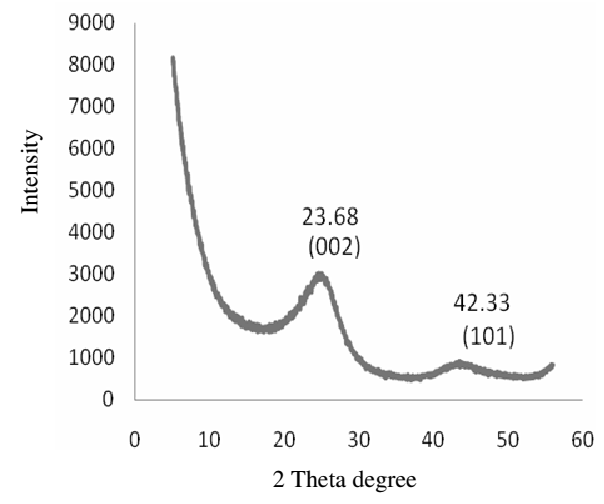

Figure 4. X-ray diffraction pattern of sooth obtained from the combustion of kerosene

\section{Conclusion}

Carbonaceous soot produced from kerosene without a catalyst precursor show the presence of significant amount of carbon nanomaterial. Raman spectroscopy and x-ray diffraction investigation shows the presence of carbon nanotubes in association with amorphous nanomaterial. The presence of silicon is recorded in the EDS analysis the source of which is unknown.

\section{Acknowledgment}

This work was supported by a research grant from the Faculty of Applied and Computer Science Research and Publications Committee of Vaal University of Technology, Vanderbijlpark.

\section{Reference}

1. Gomez-Carracedo M P, Andrade J M, Calvino M, Fernandez E, Prada D and Muniategui S, Fuel, 2003, 82(10), 1211 - 1218.

2. Chung H, Ku M-S and Lee J-S, Vib Spectrosc., 1999, 20, 155 - 163.

3. Kumar M, Kichambare P D, Sharon M, Ando Y and Zhao X, Mater Res Bull., 1999, 34(5), 791 - 801.

4. Dikio E D, Thema F T, Dikio C W and Mtunzi F M, Int J Nanotech Appl., 2010, 4(2), 117 - 124.

5. Dikio E D and Bixa N, Int J Appl Chem., 2011, 7(1), 35-42.

6. Han J T, Woo J H, Kim H S and Jee J G, Bull Korean Chem Soc., 2003, 24(12), $1771-1774$.

7. Benito P, Herrero M, Labajos F M, Rives V, Royo C, Latorre N and Monzon A, Chem Eng J., 2009, 149, 455-462. 
8. Liu J, Shao M, Chen X, Yu W, Liu X and Qian Y, J Am Chem Soc., 2003, 125(27), $8088-8089$.

9. Shao M, Li Q, Wu J, Xie B, Zhang S and Qian Y, Carbon, 2000, 40, 2961 - 2973.

10. Jin W-J, Jeon H J, Kim J H and Youk J H,.J Synth Met., 2007, 157, 454 - 459.

11. Nieto-Marquez A, Toledano D, Sanchez P, Romero A and Valverde J L, J Catal., 2010, 269, $242-251$.

12. Bystrzejewski M, Lange H, Huczko A, Baranowski P, Hubers H W, Gemming T, Pichler T, Buchner B and Rummeli M H, J S S Chem., 2008, 181, 2796 - 2803.

13. Nyamori V O, Mhlanga S D and Coville N J, J Organomet Chem., 2008, 693, $2205-2222$.

14. Burtscher H, J Aerosol Sci., 2005, 36, 896 - 932.

15. Srivastava S K, Vankar V D and Kumar V, J Thin Solid Films, 2006, 515, 1552 - 60.

16. Eftekhari A, Jafarkhani P and Moztarzadeh F, Carbon, 2006, 44, 1343 - 45.

17. Malek Abbaslou R M, Soltan J and Dalai A K, Appl Catal A: Gen., 2010, 379, $129-134$.

18. Mi H, Zhang X, Xu Y and Xiao F, Appl Surf Sci., 2010, 256(7), 2284 - 2288.

19. Ni Y, Shao M, Tong Y, Qian G and Wei X, J S S Chem., 2005, 178, 908 - 911. 


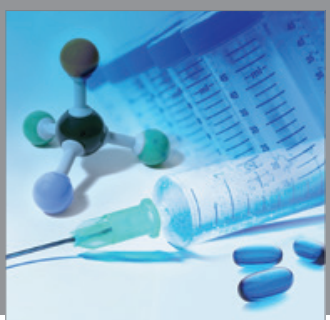

International Journal of

Medicinal Chemistry

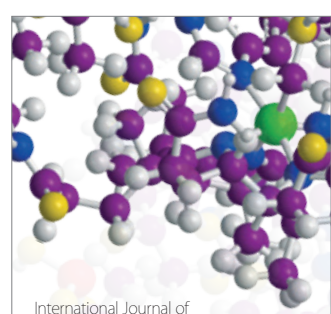

Carbohydrate Chemistry

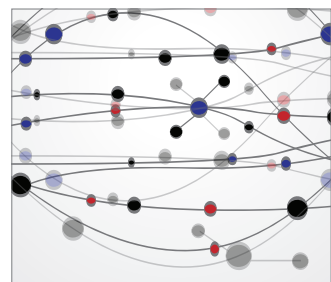

The Scientific World Journal
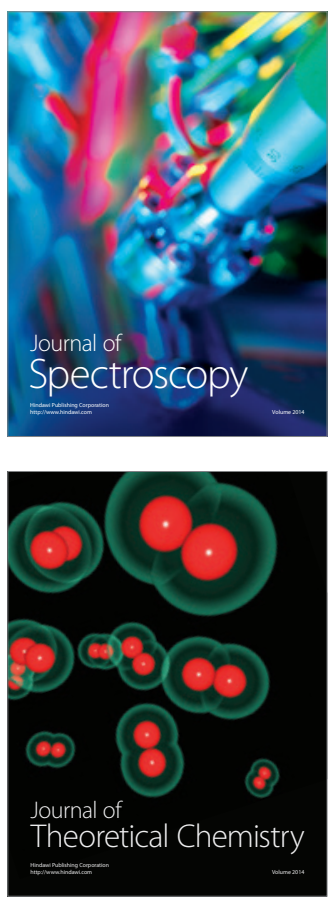
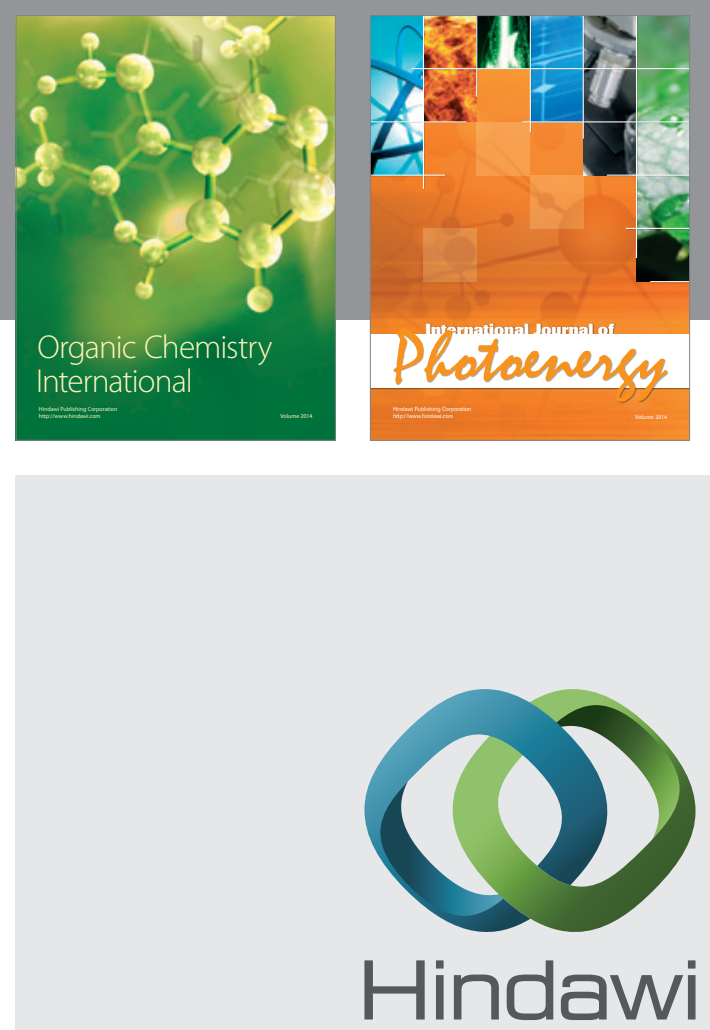

Submit your manuscripts at

http://www.hindawi.com
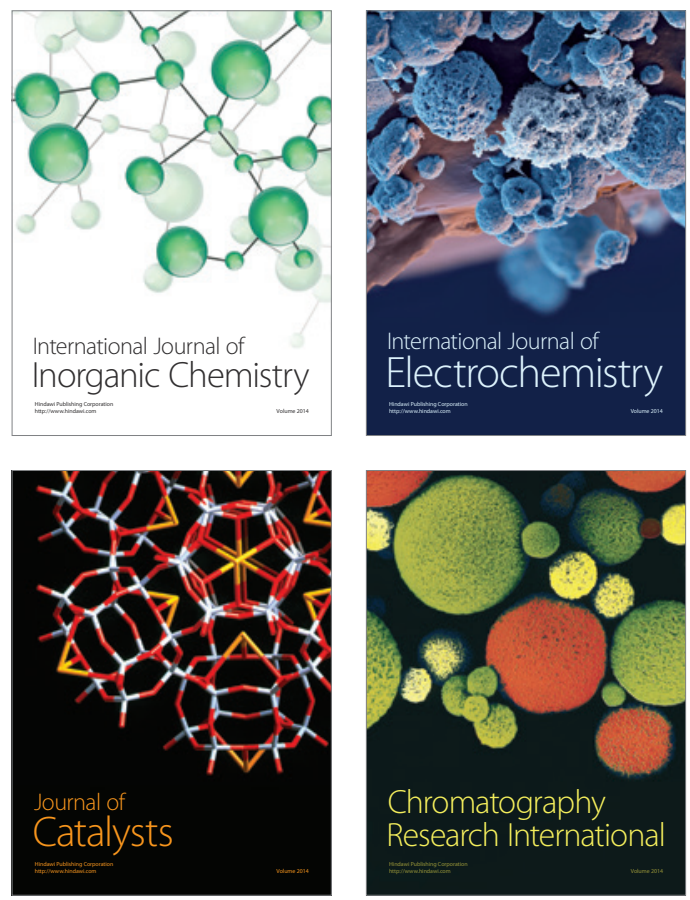
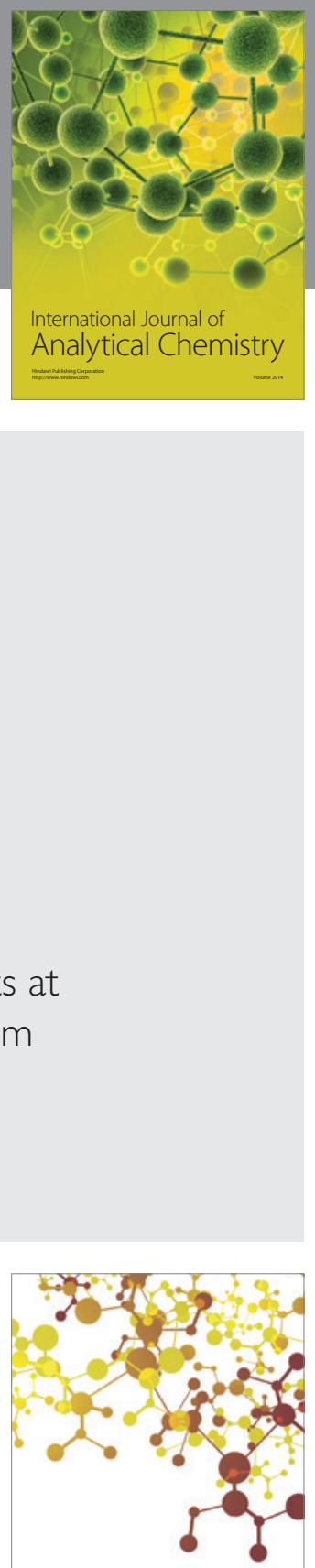

Journal of

Applied Chemistry
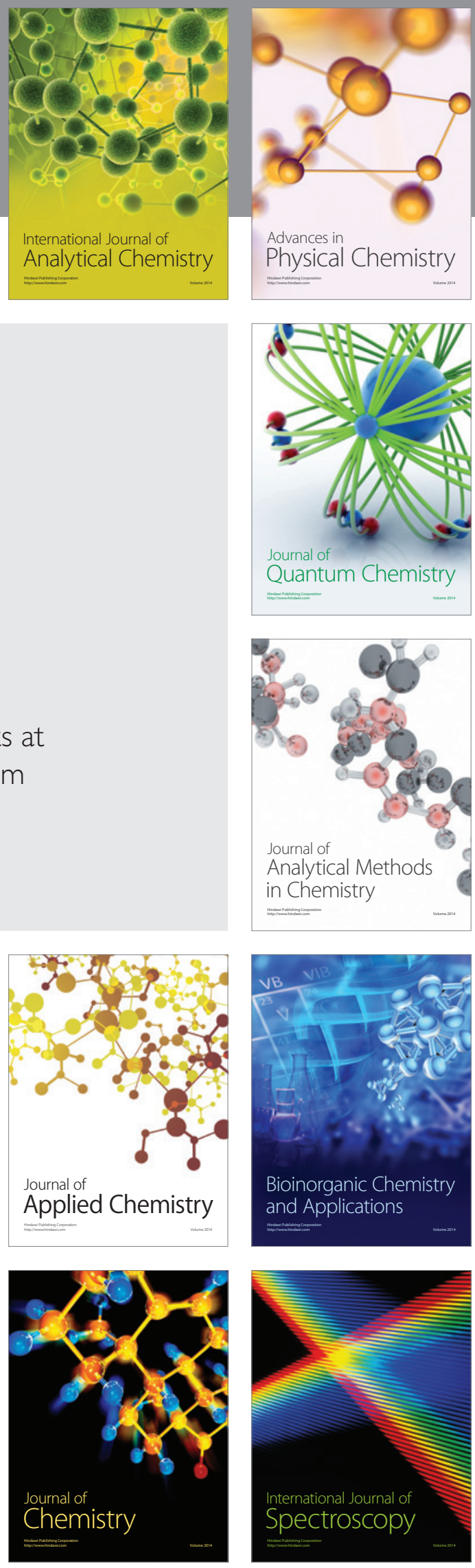